The International Journal of Engineering and Science (IJES)

|| Volume || 6 || Issue || 3 || Pages || PP 42-54 || 2017 ||

ISSN (e): $2319-1813$ ISSN (p): $2319-1805$

\title{
The Thermodynamics of Refrigeration - Principles of Natural Gas Cryogenic Process
}

\author{
Dr. Francis, I. Nweke \\ Department of Petroleum and Gas Engineering, University of Port Harcourt, Rivers state, Nigeria.
}

\begin{abstract}
-
Refrigeration can be analysed just at a conceptual system level (what purpose it must accomplish, how it can be done in principle, how it can be done in practice), or it can be analysed in more detail to include also the study of the components used in refrigeration equipment: heat exchangers, compressors, valves, absorbers, pumps, piping, supports, controls, selection, design, etc. Here, focus is on refrigeration cycles more than on the actual components used.

Since natural gas liquefies at cryogenic temperatures, i.e. temperatures well below $-100^{\circ} \mathrm{C}$, there is always a continuous boil-off of the liquefied natural gas during transportation. Accordingly, equipment needs to be provided in order to handle this boil-off.

The basic apparatus is cryogenic tanks (refrigerator), a thermal machine producing cold. The basic principle guarding this process of maintaining that low temperature is known as thermodynamic of refrigeration.

Keywords: Refrigeration, cryogenic, liquefied natural gas, Thermodynamics, Liquefaction.
\end{abstract}

Date of Submission: 21 March $2017 \quad$ Date of Accepted: 01 April 2017

\section{INTRODUCTION}

Refrigeration is the withdrawal of heat from a substance or space so that temperature lower than that of the natural surroundings is achieved. It is also the achievement of temperatures below that of the local environment. The main purpose of refrigeration is thermal conditioning (e.g. for food preservation or air conditioning). Refrigeration may be produced by

- Thermoelectric means

- Vapor compression systems

- Expansion of compressed gases

- Throttling or unrestrained expansion of gases.

Producing cold is basically different to and much more difficult than producing heat; people learnt to produce heat 500,000 years ago (in the ice ages), whereas refrigeration started only 150 years ago (in the 19th century). On mass and economic terms, the transport of liquefied natural gas (LNG) by boat is the largest commercial cryogenic application. From its source, natural gas, compressed to some $6 \mathrm{MPa}$, is first dried (removing water and liquid hydrocarbons), then sweetened (removing $\mathrm{CO}_{2}$ and sulphur compounds), lightened (butane and propane removed by cooling to $-30{ }^{\circ} \mathrm{C}$ with a propane refrigeration machine) and then fed to the cryogenic liquefier, after which nitrogen is separated, and the LNG stored aside. The cryogenic liquefier is a vapourcompression-refrigerator (with its condenser cooled by a propane refrigerator at $\square 35^{\circ} \mathrm{C}$ ) using a working fluid mixture of nitrogen, methane, ethane and propane, that cools the natural gas, at $6 \mathrm{MPa}$, down to $-135^{\circ} \mathrm{C}$, before a throttling process to atmospheric pressure yields the final $-161^{\circ} \mathrm{C}$ of storage conditions.

Thermodynamics is the study of the laws that govern the conversion of energy from one form to another, the direction in which heat will flow, and the availability of energy to do work. It is based on the concept that in an isolated system anywhere in the universe there is a measurable quantity of energy called the internal energy (U) of the system.

A thermodynamic system is that part of the universe that is under consideration. A real or imaginary boundary separates the system from the rest of the universe, which is referred to as the environment. A useful classification of thermodynamic systems is based on the nature of the boundary and the flows of matter, energy and entropy through it.

There are three kinds of systems depending on the kinds of exchanges taking place between a system and its environment:

- $\quad$ isolated systems: not exchanging heat, matter or work with their environment. An example of an isolated system would be an insulated container, such as an insulated gas cylinder. 
- closed systems: exchanging energy (heat and work) but not matter with their environment. A greenhouse is an example of a closed system exchanging heat but not work with its environment. Whether a system exchanges heat, work or both is usually thought of as a property of its boundary, which can be

- adiabatic boundary: not allowing heat exchange;

- rigid boundary: not allowing exchange of work.

- open systems: exchanging energy (heat and work) and matter with their environment. A boundary allowing matter exchange is called permeable. The ocean would be an example of an open system.

\section{THERMODYNAMICS OF REFRIGERATION}

\section{Refrigeration}

- "refrigeration is the transfer of energy in the form of heat from a colder to a hotter body, by the application of external work" (or heat).

- a refrigerator is most often a reversed 'heat engine':
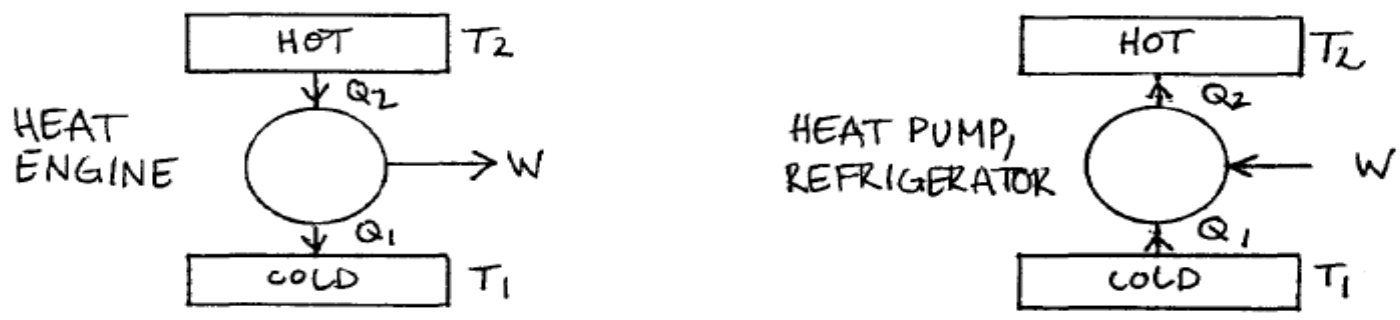

- common methods of refrigeration include:

1. the vapour compression cycle

2. the gas compression cycle

3. absorption cycle

4. thermoelectric cycle

\subsection{Definitions}

\subsubsection{The coefficient of performance (COP)}

- the 'coefficient of performance' ( $C O P$ ) of a heat pump or refrigerator is analogous to the thermal efficiency $\left(\eta_{t_{h}}\right)$ of a heat engine; both quantities define 'what you get for what you have to put in'

- for a heat engine we 'get' work output $W$, and we have to 'put in' heat $Q_{2}$ (usually in the form of a combusting fuel) to do so. Thus, from the figure above:

$$
\eta_{t h}=\frac{\text { work out }}{\text { heat in }}=\frac{W}{Q_{2}}
$$

- the useful effect of the refrigerator is the removal of heat from the cold space i.e. what we 'get' is $Q_{1}$ and we have to 'put in' work $W$ (usually from a compressor). Thus,

$$
C O P_{\text {refrig }}=\frac{\text { heat removed }}{\text { work required }}=\frac{Q_{1}}{W}
$$

- conversely, the useful effect of the heat pump is the addition of heat to a hot space i.e. we 'get' $Q_{2}$ for 'putting in' work input $W$. Thus,

$$
C O P_{\text {heat pump }}=\frac{\text { heat supplied }}{\text { work required }}=\frac{Q_{2}}{W}=\frac{W+Q_{1}}{W}=1+C O P_{\text {refrig }}
$$




\subsubsection{Refrigerating effect and capacity}

- the 'refrigerating effect' $q(J / k g)$ is the heat removed per unit mass flow of refrigerant.

- the refrigerating capacity $Q(W)$ is the rate of heat removal.

- the 'ton' is an imperial unit that is still common. It is defined as " 1 ton of refrigeration equals the heat transfer required to convert $2000 \mathrm{lbm}$ of water at $0^{\circ} \mathrm{C}$ to ice at $0^{\circ} \mathrm{C}$ in 24 hours".

$$
1 \text { ton }=12000 \mathrm{Btu} / \mathrm{h}=3.517 \mathrm{~kW}
$$

\subsection{Simple vapour compression refrigeration cycle}

- the simple vapour compressior refrigeration cycle is a reversed Carnot cycle for a condensable working fluid:

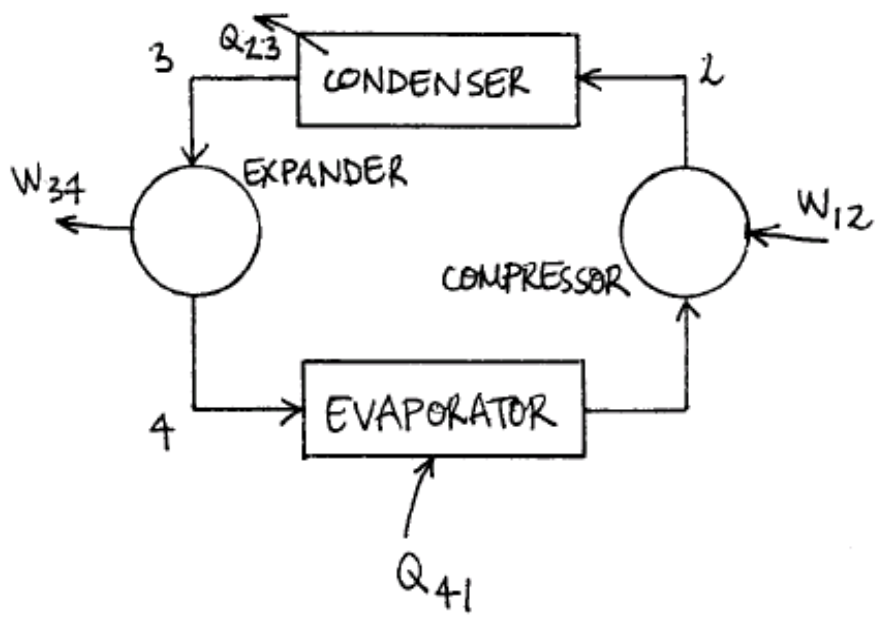

- with $T-s$ diagram:

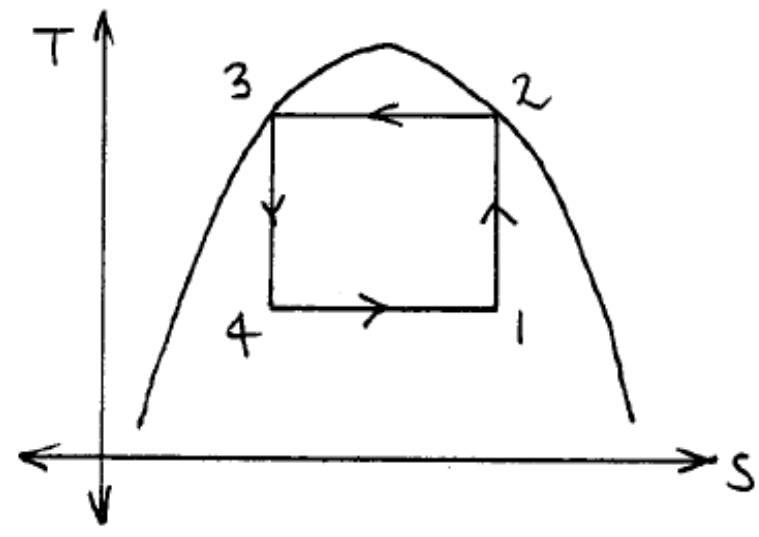

- where:

$1 \rightarrow 2$ isentropic (reversible adiabatic) compression

$2 \rightarrow 3$ isothermal heat rejection (condensation)

$3 \rightarrow 4$ isentropic (reversible adiabatic) expansion

$4 \rightarrow 1$ isothermal heat absorption (evaporation) 
- even allowing for nonisentropic compression and expansion, this cycle is impractical because process $1 \rightarrow 2$ involves the compression of a mixture of liquid and gas until all the liquid has evaporated. This is very difficult to achieve in practice, because the compression of wet mixtures is very difficult to implement mechanically.

\subsection{Practical vapour compression refrigeration cycle}

- in order avoid the practical difficulties of the simple vapour compression cycle, we make two modifications to it:

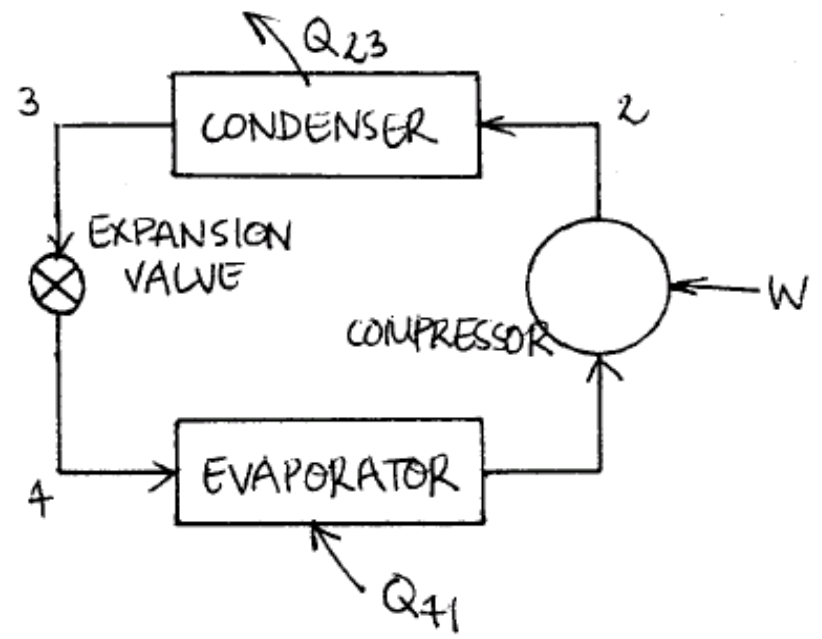

- with $T-s$ diagram:

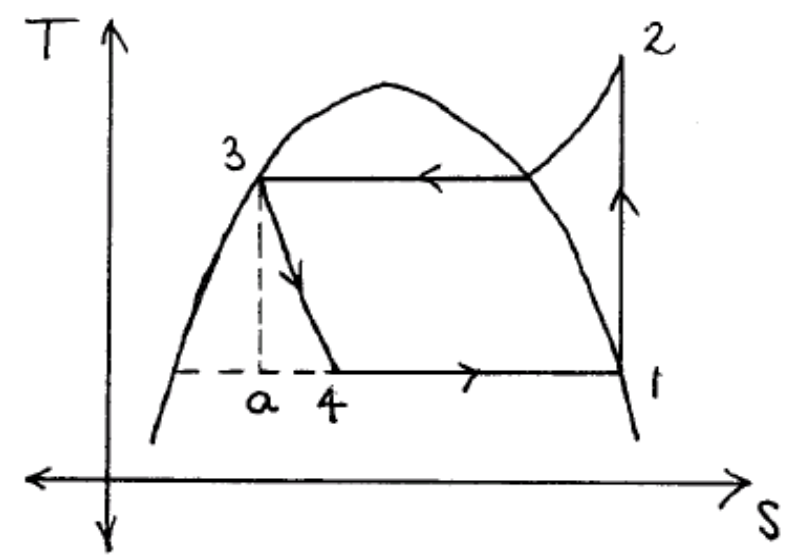

- the two modifications to the simple cycle are:

1. the expander is replaced by a throttling valve. A throttle is approximately an isenthalpic device since, from the SFEE (and neglecting the kinetic energy terms):

$$
\underset{=0}{q-\underset{=0}{W}}=\Delta h
$$

2. the fluid is fully evaporated leaving the evaporator, so the compressor handles only a gas

- since throttling creates entropy, the heat transfer in the evaporator is reduced i.e.

$h_{1}-h_{4}<h_{1}-h_{a}$ 
- for a given pressure ratio, the compressor work is larger than for the simple cycle because the compressor delivers a superheated gas

- the cycle COP is less than the COP for the equivalent ideal reversed Carnot cycle since:

1. condensation is no longer isothermal

2. throttling is inherently irreversible as is 'real' compression

\subsection{Undercooling \& superheating}

- this is a similar concept to the regenerative gas turbine:

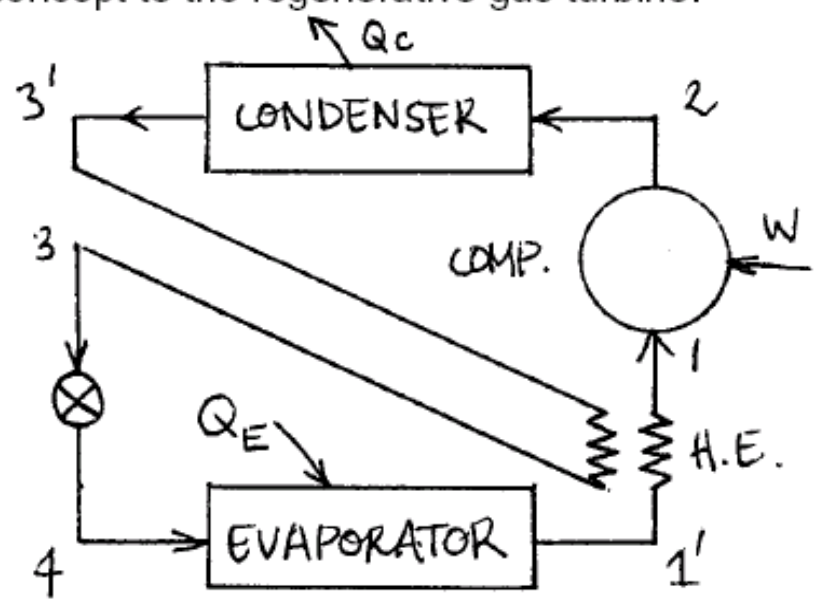

- with $T-s$ diagram:

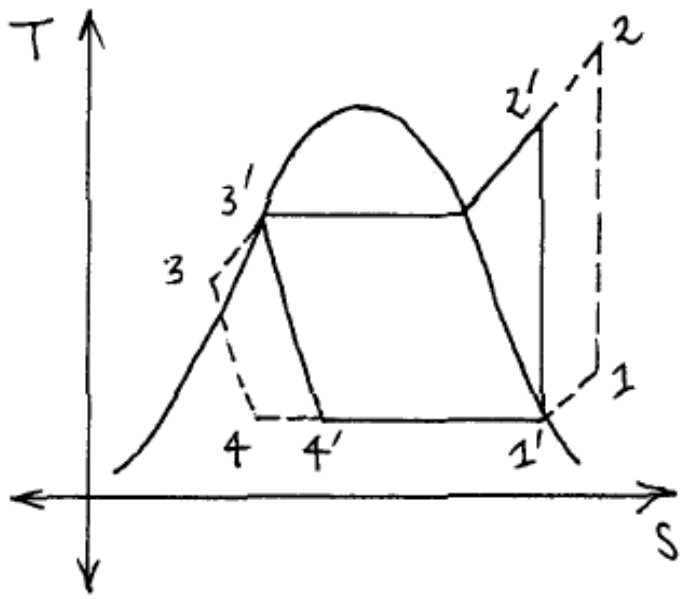

- note:

1. condensate from the condenser is cooled, increasing the heat absorbed in the evaporator. Thus, the cooling effect is increased.

2. vapour is superheated before compression, thus ensuring that no liquid exists in the compressor.

3. compressor work is increased 


\subsection{P-h diagram}

- the $P-h$ diagram is often used when studying refrigeration cycles because the condenser $q_{23}$ and evaporator $q_{41}$ heat transfer and the compressor work $w_{c}$ are easily read off the charts.

- the $P-h$ diagram for the practical vapour compression cycle is:

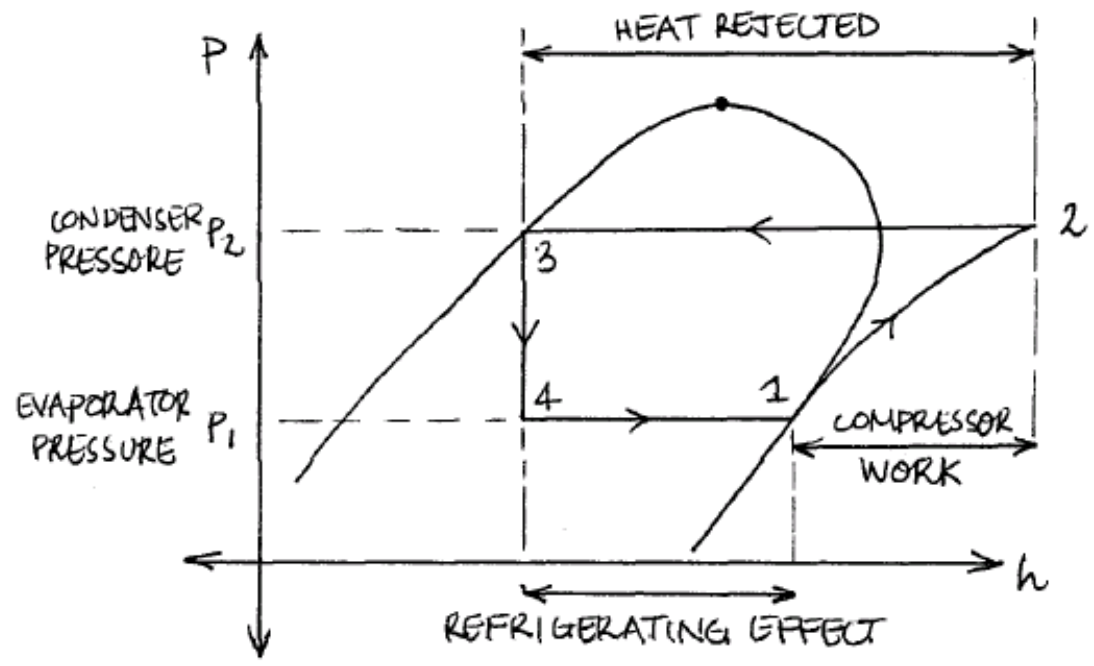

- as is shown, the practical vapour compression refrigeration cycle is comprised of two (ideally) isobaric heat transfer processes (condensation \& evaporation) and one isenthalpic process (throttling)

- from the SFEE, and neglecting the kinetic energy terms (note that we have broken the sign convection and made all terms positive in order to simplify the maths):

\begin{tabular}{|l|c|c|}
\hline \multicolumn{1}{|c|}{ quantity } & $q$ & $w$ \\
\hline compressor work & 0 & $w_{c}=h_{2}-h_{1}$ \\
\hline condenser heat transfer & $q_{23}=h_{2}-h_{3}$ & 0 \\
\hline evaporator heat transfer & $q_{41}=h_{1}-h_{4}$ & 0 \\
\hline throttling $\left(h_{3}=h_{4}\right)$ & 0 & 0 \\
\hline
\end{tabular}

- also, the $P-h$ diagram shows that:

$$
q_{41}+w_{c}=q_{32}
$$

- it follows that the COP of various devices can be determined:

$$
\begin{aligned}
C O P_{\text {refrig }} & =\frac{q_{41}}{w_{C}}=\frac{q_{41}}{q_{23}-q_{41}} \\
C O P_{\text {heat pump }} & =\frac{q_{23}}{w_{C}}=\frac{q_{23}}{q_{23}-q_{41}}=\frac{q_{41}+q_{23}-q_{41}}{q_{23}-q_{41}}=C O P_{\text {reffig }}+1
\end{aligned}
$$




\subsection{Refrigerants}

- the working fluid within the refrigeration cycle is referred to as a 'refrigerant'. Refrigerants should have the following properties:

\begin{tabular}{|l|l|l|}
\hline \multicolumn{1}{|c|}{ property } & \multicolumn{1}{c|}{ desired } & \multicolumn{1}{c|}{ explanation } \\
\hline $\begin{array}{l}\text { Critical } \\
\text { temperature }\end{array}$ & $\begin{array}{l}\text { > condenser } \\
\text { temperature }\end{array}$ & $\begin{array}{l}\text { To approach the Carnot cycle and } \\
\text { hence achieve high COP }\end{array}$ \\
\hline $\begin{array}{l}\text { Freezing } \\
\text { temperature }\end{array}$ & Low & $\begin{array}{l}\text { Liquid only in evaporator. No } \\
\text { freezing }\end{array}$ \\
\hline $\begin{array}{l}\text { Saturation } \\
\text { pressure }\end{array}$ & $\begin{array}{l}\text { Above } \\
\text { atmospheric }\end{array}$ & Avoid air leaks into the system. \\
\hline $\begin{array}{l}\text { Evaporation } \\
\text { enthalpy }\end{array}$ & High & Reduces mass flow rate. \\
\hline $\begin{array}{l}\text { Specific volume } \\
\text { Stability }\end{array}$ & Low & $\begin{array}{l}\text { Reduces compressor work and } \\
\text { system size. }\end{array}$ \\
\hline $\begin{array}{l}\text { Thermal } \\
\text { conductivity }\end{array}$ & Hood & Both pure substances and mixtures \\
\hline Solubility & Low & good heat transfer rates \\
\hline $\begin{array}{l}\text { Toxicity/ } \\
\text { Irritancy }\end{array}$ & Low & $\begin{array}{l}\text { Avoid water contamination. } \\
\text { Avoid oil contamination }\end{array}$ \\
\hline Non-Flammable & & $\begin{array}{l}\text { Avoid poisoning. } \\
\text { Convenient handling. }\end{array}$ \\
\hline Detectability & Good & $\begin{array}{l}\text { Safety in charging, handling. } \\
\text { Safety if leaks. }\end{array}$ \\
\hline Ozone depletion & None & For tracing leaks. \\
\hline Cost & low & Prevent ozone layer depletion. \\
\hline
\end{tabular}

- examples of common inorganic refrigerants:

1. ammonia $\left(\mathrm{NH}_{3}\right)$

2. carbon dioxide $\left(\mathrm{CO}_{2}\right)$

3. sulphur dioxide $\left(\mathrm{SO}_{2}\right)$

- examples of common organic refrigerants:

1. Trichlorofluoromethane $\left(\mathrm{CFCl}_{3}\right)$ - 'Freon 11' or 'R11'

2. Dichlorodifluoromethane $\left(\mathrm{CF}_{2} \mathrm{Cl}_{2}\right)$ - 'Freon 12' or 'R12'

3. monofluorodichloromethane $\left(\mathrm{CHFCl}_{2}\right)$ - 'Freon 21' or 'R21'

4. methylchloride $\left(\mathrm{CH}_{3} \mathrm{Cl}\right)$

5. triflourotrichloroethane $\left(\mathrm{C}_{2} \mathrm{~F}_{3} \mathrm{Cl}_{3}\right)$ - 'Freon 113' or 'R113'

6. Tetrafluoroethane $\left(\mathrm{CH}_{2} \mathrm{FCF}_{3}\right)$ - 'Freon 134a' or 'R134a'

- in order to protect the ozone layer, new domestic refrigerators and airconditioning units use hydroflourocarbons (HFC's) as a replacement refrigerant chloroflourocarbons (CFC's). eg. R134a is a replacement for R12 
- looking at the properties of ammonia and R12:

\begin{tabular}{|c|c|c|c|c|}
\hline Property & \multicolumn{2}{|c|}{ Ammonia } & \multicolumn{2}{|c|}{ Freon 12} \\
\hline Critical temp & yes & $132^{\circ} \mathrm{C}$ & yes & $112^{\circ} \mathrm{C}$ \\
\hline Freezing temp & yes & $-78^{\circ} \mathrm{C}$ & yes & $-158^{\circ} \mathrm{C}$ \\
\hline $\begin{array}{l}\text { Saturation } \\
\text { pressure }\end{array}$ & yes & $\begin{array}{l}>1 \mathrm{~atm} \text {, boils at } \\
-33^{\circ} \mathrm{C} @ 1 \mathrm{~atm}\end{array}$ & yes & $>1 \mathrm{~atm}$ \\
\hline $\begin{array}{l}\text { Evaporation } \\
\text { enthalpy }\end{array}$ & Yes & Very high & no & Only $1 / 8 \mathrm{NH}_{3}$ \\
\hline Specific volume & Yes & & yes & \\
\hline Stability & No & $\begin{array}{l}\text { Attacks } \mathrm{Cu} \text { and } \\
\text { alloys of } \mathrm{Cu}\end{array}$ & yes & Non-corrosive \\
\hline $\begin{array}{l}\text { Thermal } \\
\text { conductivity }\end{array}$ & Yes & High & & Only $1 / 10 \mathrm{NH}_{3}$ \\
\hline Solubility & $\begin{array}{l}\text { No } \\
\text { Yes }\end{array}$ & $\begin{array}{l}\text { Soluble in water } \\
\text { Insoluble in oil }\end{array}$ & $\begin{array}{l}\text { yes } \\
\text { no }\end{array}$ & $\begin{array}{l}\text { Insoluble } \\
\text { Miscable }\end{array}$ \\
\hline $\begin{array}{l}\text { Toxicity/ } \\
\text { Irritancy }\end{array}$ & $\begin{array}{l}\text { No } \\
\text { No }\end{array}$ & $\begin{array}{l}\text { Toxic } \\
\text { Irritates eyes }\end{array}$ & $\begin{array}{l}\text { yes } \\
\text { yes }\end{array}$ & $\begin{array}{l}\text { Non-toxic } \\
\text { OK }\end{array}$ \\
\hline Non-flammable & $\mathrm{No}$ & Ignitable & yes & \\
\hline Detectability & & Smells & yes & $\begin{array}{l}\text { no smell, special } \\
\text { detector needed }\end{array}$ \\
\hline Ozone depletion & Yes & No ozone effect & & Very bad \\
\hline Cost & Yes & Very cheap & & Expensive \\
\hline
\end{tabular}

- the more environmentally friendly R134a has very similar properties to R12, but does not cause ozone depletion.

\subsection{Ammonia $\left(\mathrm{NH}_{3}\right)$ absorption refrigerator}

- large scale refrigeration plants often feature this cycle because ammonia has a high specific enthalpy of evaporation (therefore reducing plant size) and the pump specific work is relatively small.

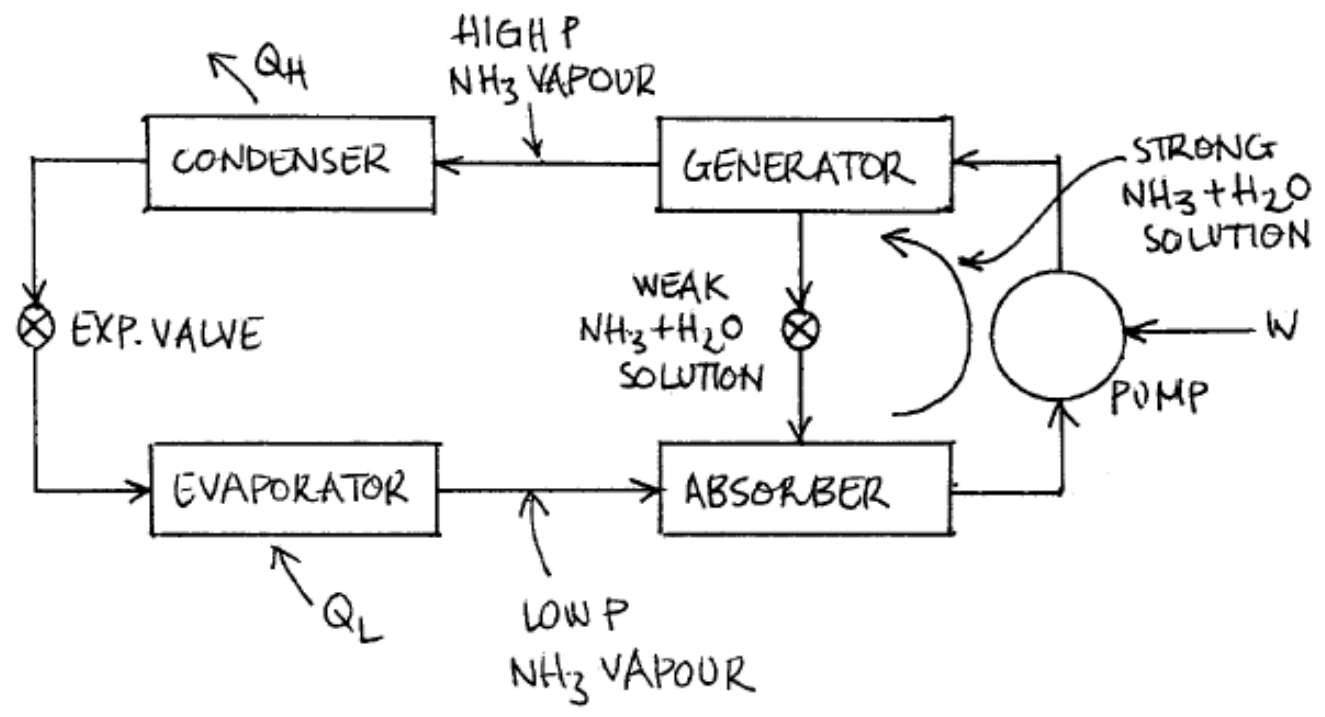


- the objective of this cycle is to replace the vapour compressor with a liquid pump, since the pumping of liquid typically requires much less energy. This is clear since:

$$
\begin{aligned}
w & =-\int v d P \\
& \simeq-v\left(P_{2}-P_{1}\right) \text { for a liquid }
\end{aligned}
$$

- thus, for a given pressure ratio, the work required to pump a liquid is much smaller than that required to compress a gas since the specific volume $v$ of the liquid is much smaller (density $\rho$ is greater).

- the process can be divided up as follows:

1. the condensation, expansion and evaporation processes consist of $\mathrm{NH}_{3}$ vapour only, and are in principle the same as these processes in the vapour compression cycle

2. the $\mathrm{NH}_{3}$ is absorbed into a solution with $\mathrm{H}_{2} \mathrm{O}$ in the absorber

3. the liquid solution of $\mathrm{NH}_{3}+\mathrm{H}_{2} \mathrm{O}$ has its pressure raised by the pump

4. the generator is heated to release $\mathrm{NH}_{3}$, but $\mathrm{H}_{2} \mathrm{O}$ stays in liquid phase because it has a higher boiling temperature

5. the $\mathrm{NH}_{3}$ proceeds around the cycle and the $\mathrm{H}_{2} \mathrm{O}$ is throttled back to low pressure and returns to the absorber

drawbacks:

1. it can be difficult to keep $\mathrm{H}_{2} \mathrm{O}$ out of the $\mathrm{NH}_{3}$ loop, where the $\mathrm{H}_{2} \mathrm{O}$ may freeze in the evaporator.

2. cycle requires more components than vapour compression cycle

\subsection{Air cycle refrigeration}

- air cycle refrigeration is the Joule/Brayton cycle in reverse:

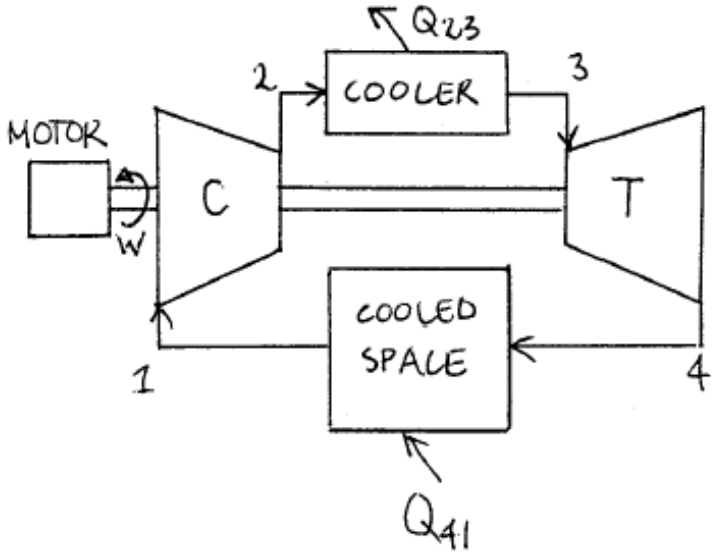


- and with an ideal compressor and turbine, the $T-s$ diagram is:

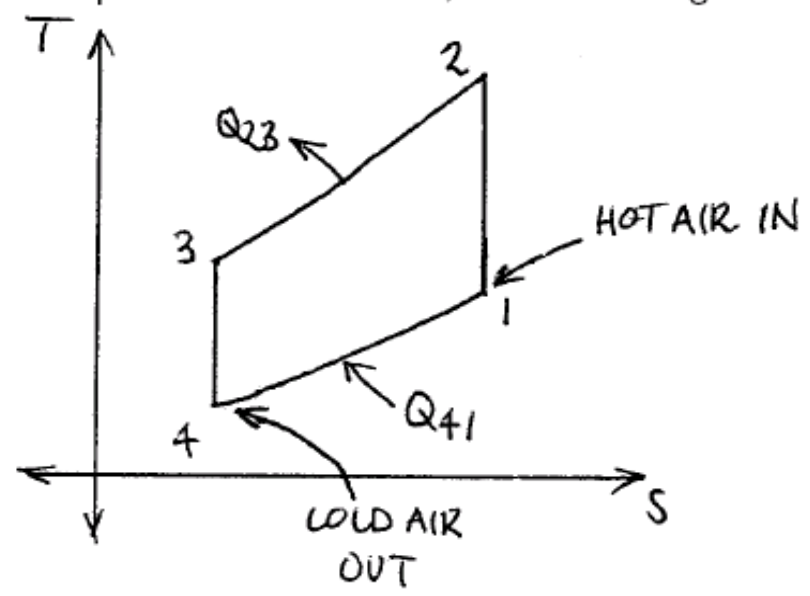

- note:

1. unlike the previous cycles, phase changes do not occur within this cycle and it features only a gas

2. we must have an expansion turbine, not a throttle

3. in order to achieve reasonable $C O P$, we must have high $\eta_{c}$ and $\eta_{t}$

- coefficient of performance:

$$
C O P \equiv \frac{Q_{i n}}{W_{t n}}=\frac{Q_{41}}{W_{c}-W_{t}}
$$

- it follows that:

$$
\begin{aligned}
C O P & =\frac{\chi_{p}\left(T_{1}-T_{4}\right)}{\chi_{p}\left(T_{2}-T_{1}\right)-\chi_{\mathbf{p}}\left(T_{3}-T_{4}\right)} \\
& =\frac{\left(1-\frac{T_{4}}{T_{1}}\right)}{\left(\frac{T_{2}}{T_{1}}-1\right)-\frac{T_{4}}{T_{1}}\left(\frac{T_{3}}{T_{4}}-1\right)}
\end{aligned}
$$

- note, as discussed earlier, the static temperature is approximately equal to the stagnation temperature if the kinetic energy of the flow is small.

- since processes $1 \rightarrow 2$ and $3 \rightarrow 4$ are isentropic, let:

$$
\frac{T_{2}}{T_{1}}=r_{p}^{\frac{\gamma-1}{\gamma}}=\frac{T_{3}}{T_{4}}
$$

- where $r_{p}=p_{2} / p_{1}=p_{3} / p_{4}$

- thus:

$$
C O P=\frac{\left(1-\frac{T_{4}}{T_{1}}\right)}{\left(r_{p}^{\frac{\gamma-1}{\gamma}}-1\right)-\frac{T_{4}}{T_{1}}\left(r_{p}^{\frac{\gamma-1}{\gamma}}-1\right)}
$$


- and finally:

$$
C O P=\frac{1}{\left(r_{p}^{\frac{\gamma-1}{\gamma}}-1\right)}
$$

- which shows that the COP reduces with increased pressure ratio cf. the increase in $\eta_{t h}$ with pressure ratio for the ideal gas turbine cycle shown earlier.

\subsection{Liquefaction of gases}

- liquefaction uses the gas to be liquefied as the working fluid

- the liquefaction process must bring the gas state to below its critical point in order for condensation to occur

- critical points of common substances:

\begin{tabular}{|l|l|l|}
\hline Substance & $T_{\text {CRIT }}(\mathrm{K})$ & $\mathrm{P}_{\text {CRIT }}(\mathrm{MPa})$ \\
\hline $\mathrm{CO}_{2}$ & 304 & 7.39 \\
\hline $\mathrm{O}_{2}$ & 155 & 5.08 \\
\hline $\mathrm{N}_{2}$ & 126 & 3.39 \\
\hline $\mathrm{H}_{2}$ & 33.3 & 1.30 \\
\hline $\mathrm{Ar}$ & 151 & 4.86 \\
\hline
\end{tabular}

- a sketch of a typical liquefaction process:

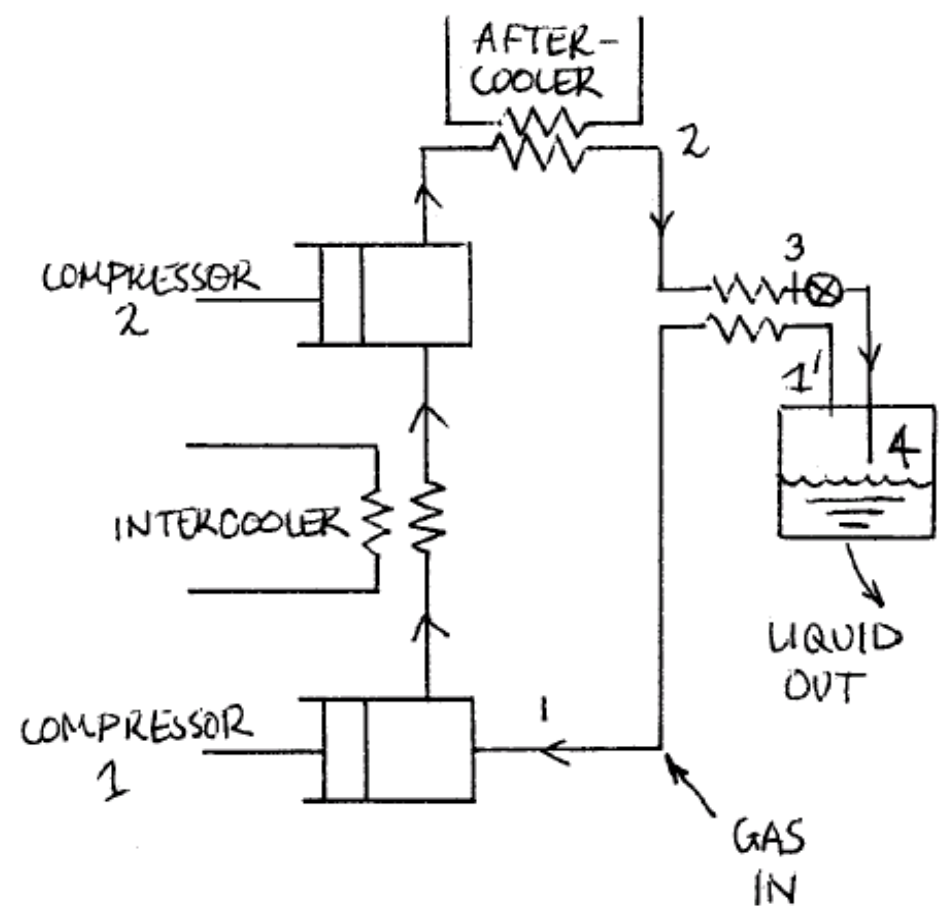


- and its corresponding $T-s$ diagram:

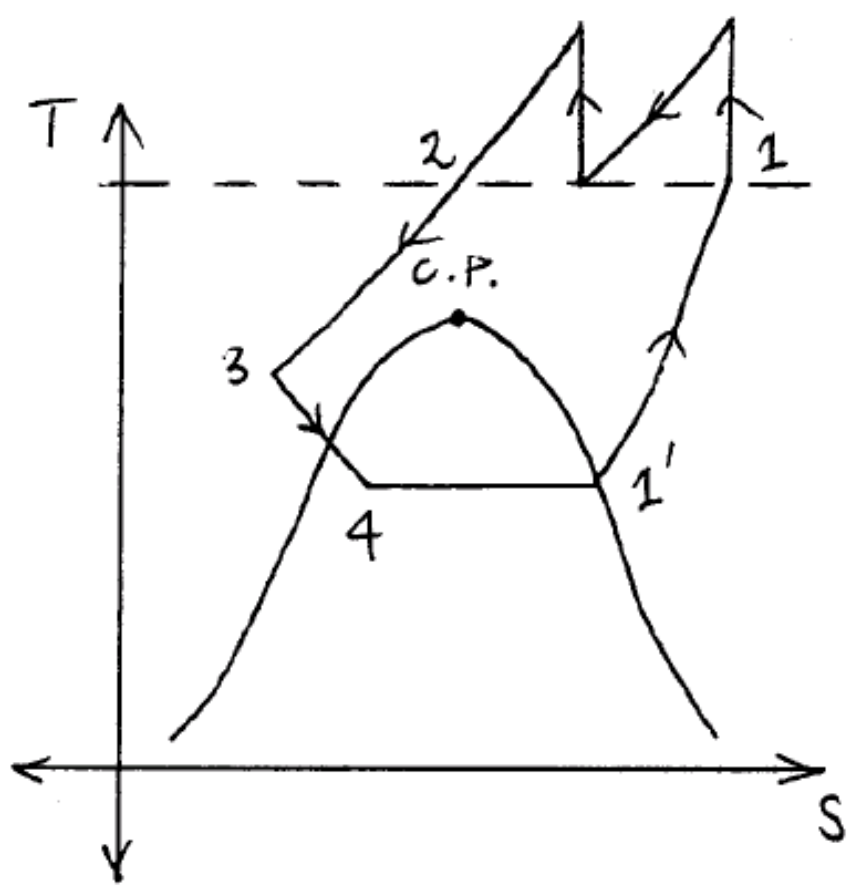

IV. CONCLUSION

The information provided in this paper and the level of detail for the thermodynamic of refrigeration are intended to demonstrate the competitive edge of this concept with respect to:

- Safety (minimum hydrocarbon inventory in process)

- Reliability

- Operability

• Energy efficiency (minimal CO2-emission, high condensate yield)

- Economics

- Flexibility

Despite the fact that not all issues were addressed in full detail, it is clear that the refrigeration process can be made very efficient and installed at a sufficiently low cost to be truly competitive.

The development of this concept requires further evaluation with respect to the following issues:

- Integration of the LNG plant with the ship's systems

- Off-loading (this is a separate technology development)

- (Comparative) Safety studies

- More detailed cost estimate of the LNG vessel, off-loading and mooring systems

- Availability \& reliability Study

This truly innovative refrigeration technology has lead to a breakthrough in LNG production.

The process of Thermodynamics of refrigeration devices is overwhelming, and refrigeration devices are used in operating applications such as:

1. Upstream: Associated Gas Liquefaction

2. Gas Liquefaction during extended well testing

3. Hydrocarbon dew pointing in gas treatment facilities

4. Remote, marginal field developments

5. Air Separation on drilling rigs (N2 for well injection)

6. Air Separation in Gas to Liquids plants

7. LNG: Storage and Carrier boil-off re-liquefaction

8. Petrochemical: C2, C3-splitting, etc.

9. Energy: Peak Shaving and load management for transmission systems

10. LNG as feedstock for remote, small IPP's 
11. Other: $\mathrm{LNG}$ vehicle fuelling for fleet operations

12. Coal bed Methane Liquefaction

13. VOC Recovery on tank farms

14. CO2-recovery, e.g. horticultural

\section{REFERENCES}

[1]. A.J. Finn, G.L. Johnson, and T.R. Tomlinson: "Developments in natural gas liquefaction", from Hydrocarbon Processing, April 1999

[2]. Energy Information Administration: "Liquefied Natural Gas (LNG) Fact sheet”, October 1998, Published by the United Stated Department of Energy.

[3]. G.W. Swift: "Thermo acoustics: A unifying perspective for some engines and refrigerators" LA-UR\#99-895 (Fourth Draft 1999). Condensed Matter \& Thermal Physics Group, Los Alamos National Laboratory, Los Alamos, New Mexico (available at: www.lanl.gov/thermoacoustics/)

[4]. J.V. Wagner (Fluor Daniel Canada): "Canadian offshore oil production - associated gas utilization alternatives." presented at Monetizing Stranded Gas Reserves '99, Houston Dec. '99

[5]. P.H. Ceperley: "A pistonless Stirling engine - The travelling wave heat engine"

[6]. Journal Acoustical Society of America no.66, '79

[7]. S. Backhaus \& G.W. Swift: “A Thermo-Stirling heat engine”, Nature, vol. 399 1999, p. 335 - 338 . Condensed Matter \& Thermal Physics Group, Los Alamos National Laboratory, Los Alamos, New Mexico

[8]. S. Backhaus \& G.W. Swift: “A Thermo-Stirling heat engine: detailed study”, LA-UR\# 99-2283, 26 May 1999. Condensed Matter \& Thermal Physics Group, Los Alamos National Laboratory, Los Alamos, New Mexico

[9]. To be published in Journal of the Acoustical Society of America, 2000

[10]. W.C. van Wijngaarden: "Thermodynamics of Refrigeration - A Stirring Concept for Offshore Associated Gas Liquefaction" Paper presented at Monetizing Stranded Gas Reserves '99, Houston Dec. '99

\section{BIOGRAPHY:}

DR. FRANCIS, I. NWEKE, had a first degree in Petroleum Engineering from Federal University of Technology, Owerri, Imo State, Nigeria. He obtained his master's degree in Gas Engineering from University of Port Harcourt, Rivers state, Nigeria and Ph D degree in Drilling Engineering in the same University of Port Harcourt, where he developed an analytical model on pore pressure prediction in planning HPHT wells.

$\mathrm{He}$ is currently working as an Asst. Manager in Nigerian Agip Oil Company (Eni International) in Offshore Projects/ NOA wells with 14 years working experience.

$\mathrm{He}$ is a member, Society of Petroleum Engineers, International (SPE). Membership number: 3001075.

Registered member - Council for the Regulation of Engineering in Nigeria - (COREN). Membership number: R. 15,511 . 